\title{
(4tinerarius

\section{VAMOS DAR A MEIA-VOLTA, VOLTA E MEIA VAMOS DAR: O BRINQUEDO CANTADO E SUAS INFLUÊNCIAS NO DESENVOLVIMENTO INFANTIL}

\author{
NOGUEIRA, Leila Carvalho - FATERFIR \\ nogueiraley@ hotmail.com \\ LIMA, Laís Leni Oliveira - UFG/CAJ \\ laisleni@yahoo.com.br
}

\section{RESUMO}

O objetivo deste artigo $^{1}$ é analisar e compreender as implicações do brinquedo cantado no desenvolvimento infantil. Entendemos que, quando estamos muito próximos ou envolvidos com alguma questão, ou quando estamos muito distantes delas, corremos o risco de não as compreendermos bem. Ambas as atitudes são prejudiciais à análise e ao entendimento do nosso objeto de estudo. Assim, ao abordar a questão do "Brinquedo cantado e suas influências na Educação Infantil (EI)" procuramos, ao mesmo tempo, não mergulharmos e ficarmos presos em nossa prática, como também não nos distanciarmos dela, mas, encontrar um modo de aproximação e afastamento equilibrado para compreendê-la. Demos ênfase aos referenciais teóricos, sem, contudo, deixar de lado nossas experiências em sala de aula para enriquecê-los. Fizemos registros sobre o brinquedo cantado e sua inserção na EI, analisando à luz dos autores: Vygotsky (1998, 2003, 2001), Vigotskii, Luria e Leontiev (2001), Leontiev (2001), Arce (2006), Rego (1995), Machado (1986), Marsiglia (2011), Duarte (2007), Galvão (1995), dentre outros. A partir dos resultados deste estudo, entendemos que as brincadeiras de roda, as canções de ninar e outras manifestações folclóricas sempre estiveram presentes na vivência do homem. A escola tem um importante papel de incentivar os brinquedos cantados, pois estes trazem elementos de uma totalidade que permite explorar as potencialidades do ser humano e um conhecimento em si, que não pode ser descartado, sob pena, de cercear os princípios da liberdade e construção da identidade da criança.

Palavras-chaves: Brinquedo cantado. Educação infantil. Desenvolvimento.

\begin{abstract}
The objective of this article is analyzing and understanding the toy implications sung in the childhood development. We so understand that, while too close or into some sort of subject, or too far from them, we are at risk of not understanding them well. Both attitudes are harmful to the analysis so is to our object of study. Thus, as we approached the matter "Singing Toy and its influence over the Children Education (CE)" we seek, at

\footnotetext{
${ }^{1}$ Este estudo refere-se a uma pesquisa de dissertação de mestrado, realizada no Programa de PósGraduação da Faculdade de Teologia e Filosofia Fides Reformata - FATEEFFIR, do Mestrado em Educação Holística (NOGUEIRA, 2014). Trazemos neste texto, parte dos dados desta pesquisa.
} 


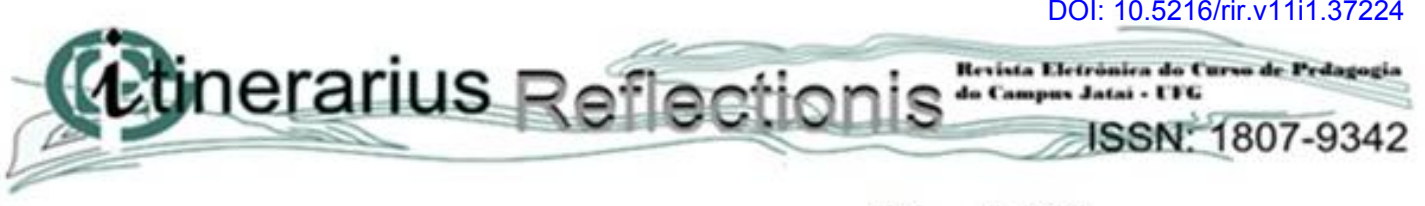

v.11, n. 1,2015

the same time, not to dive and get stuck into our practice, as well as not getting away from it, yet, finding an approaching way and a balanced getaway in order to understand them: We give emphasis to the theorical basis, nonetheless, leave not aside our experiences in the classroom to enrich them. We made a record in which the toy sings and its insertion in CE, analyzing: Vygotsky (1998, 2003, 2001), Vigotskii, Luria e Leontiev (2001), Leontiev (2001), Arce (2006), Rego (1995), Machado (1986), Marsiglia (2011), Duarte (2007), Galvão (1995), et al. From the results of this study, we understand that "brincadeiras de roda" (cultural Brazilian child's play), the lullabies and other folkloric manifestations had always been present in the mankind's living experiences. Schools has an important role in encouraging the singing toys, for these ones bring up elements at full, allowing to explore the human being's potential skills and some knowledge itself shall not be discarded, under penalty of scrimping the liberty principles and the building up of the child's identity.

Key-Word: Singing toy. Child education. Development.

\section{CONSIDERAÇÕES INICIAIS}

Este trabalho vem dar continuidade aos estudos que realizamos durante o curso de graduação em Normal Superior, no campo das disciplinas de Didática, Metodologia de Ensino, Sociologia e Psicologia, com o objetivo de melhor compreender as implicações do brinquedo cantado no desenvolvimento infantil. Resolvemos aprofundar o tema em questão, considerando ainda a escassez e a brevidade de oficinas de músicas e cursos de contação de histórias dentre outros, destinados à EI, promovidos por instituições formadoras nos cursos de formação continuada.

Várias razões motivaram a escolha desta teoria que orienta este trabalho. Durante as leituras, percebemos que Vigotski ${ }^{2}$ traz elementos significativos para compreender diferentes temas sobre a educação. Outro aspecto que nos chamou a atenção refere-se à contemporaneidade de seus conteúdos e sua proposta de estudo, a contextualização da criança inserida diretamente em seu meio, retirando de suas próprias vivências, por meio do processo de internalização das características socioculturais, os recursos para o seu desenvolvimento. Ainda, baseado neste estudioso, buscamos compreender as complexidades do desenvolvimento humano, o qual, diferentemente dos animais, como ser humano, tudo que tem de humano, provém da sua

\footnotetext{
${ }^{2}$ Em relação à grafia do nome deste autor, adotaremos a padronização brasileira (Vigotski), exceto nas citações, nas quais seguiremos a disposição na fonte.
} 


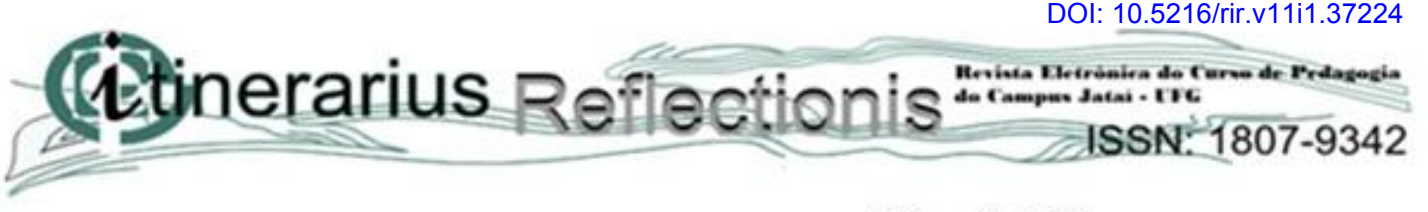

$$
\text { v.11, n. } 1,2015
$$

vida em sociedade. O trabalho humano produz a cultura material e intelectual. Essa apropriação da cultura é essencial ao desenvolvimento do sujeito e ocorre por meio de mediação de outros indivíduos.

Assim, buscamos em Vigotski o entendimento desse conhecimento por intermédio do trabalho do professor com o brinquedo cantado. Uma das mais significativas contribuições das teses que Vigotski (1998) formulou está na tentativa de explicar como o processo de desenvolvimento é socialmente constituído, por isso seu interesse pela infância.

Pesquisando sobre esse tema, optamos por direcionar nossos estudos enfocando-o conforme a teoria sócio-histórica de Vigotski, que trata da identificação das características que são próprias do comportamento humano e, a partir dessa identificação, buscamos levantar hipóteses a fim de analisar como e quando ocorre essa caracterização e se desenvolve durante toda a vida do indivíduo.

Partindo desse pressuposto, acreditamos que o brinquedo cantado tem essa magia de contagiar emocionalmente a todos que dele participam. Isso sem falar de toda a gama de conhecimentos que pode ser mediado por meio dessa atividade. Assim, a exposição deste artigo está organizada em duas seções. Na primeira, tratamos do brinquedo cantado e o desenvolvimento infantil na perspectiva vigotskiana. Seguindo essa teoria, abordamos em segundo momento sua inserção na EI.

\section{O BRINQUEDO CANTADO E O DESENVOLVIMENTO INFANTIL NA PERSPECTIVA VIGOTSKIANA}

Pretendemos nesta seção apresentar os pontos considerados fundamentais para o entendimento e o significado da importância do brinquedo cantado na Educação Infantil (EI) e como este influencia o desenvolvimento da criança. Para que alcançássemos este objetivo sentimos a necessidade de fundamentar esta pesquisa seguindo uma das tendências da psicologia que trata dos aspectos inerentes a eles, como desenvolvimento global do indivíduo.

De acordo com Rego (1995), a teoria sócio interacionista de Vigotski, objetiva caracterizar os aspectos tipicamente humanos do comportamento e elaborar 


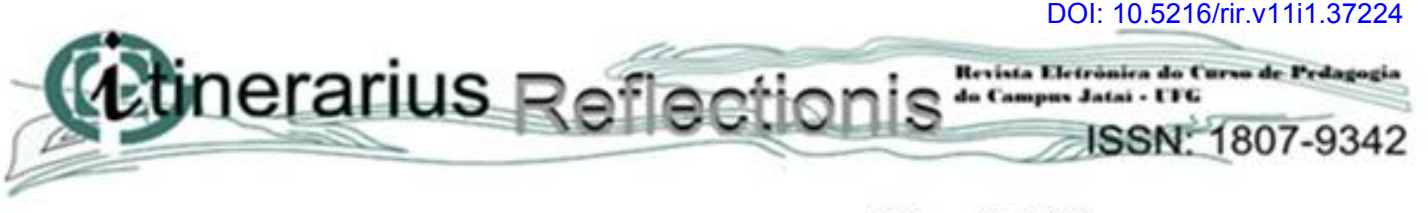

v.11, n. 1,2015

hipóteses de como essas características ocorreram e se desenvolveram ao longo da história humana.

Nesse sentido, entendemos que um campo consensual em torno do valor educativo da instituição de EI passou a ser definido e entendido a partir de algumas premissas básicas, entre as quais o desenvolvimento da criança fica condicionado às inter-relações que ela mantém com o meio social no qual esteja inserida, isto é, suas atitudes, sua personalidade, seu desenvolvimento como um todo será construído a partir de suas vivências com pessoas ligadas a ela no seu cotidiano. Logo, pode-se estabelecer o sentido de que o homem é um ser social e biológico, características estas que estão intrinsecamente relacionadas.

Dessa forma, para entender essas implicações e possibilidades dessa relação com um trabalho educativo comprometido com a mudança da sociedade é preciso pautar-se no pressuposto de que a criança de zero a cinco anos tem características e necessidades diferentes de outras faixas etárias, que requer cuidado e atenção por parte do adulto e, se negligenciadas, coloca-se em risco a sobrevivência da própria criança em relação ao seu desenvolvimento posterior.

Partimos, assim, do pressuposto de que a possibilidade de apropriação do conhecimento se faz presente nas interações sociais desde que a criança nasce. Desse modo, acreditamos que o brinquedo cantado, tem essa magia de contagiar emocionalmente a todos que dele participam. De acordo com Galvão (1995), mediante jogos, danças, canto, as pessoas realizam simultaneamente gestos e atitudes semelhantes, entregando-se aos mesmos ritmos. Essa vivência dos membros do mesmo grupo, com um mesmo movimento rítmico, proporciona sensibilidade e envolve a todos numa sintonia e emoção.

De acordo com a autora mencionada, essa forma de propiciar à criança interações com o grupo das mais diferentes naturezas, numa diversidade de elementos, contribui para o enriquecimento do universo infantil. Isso, sem falar de toda gama de conhecimentos que pode ser transmitida por meio dessa atividade. Nessa perspectiva, entendemos que a criança e o conhecimento se interagem e se transformam mutuamente. 


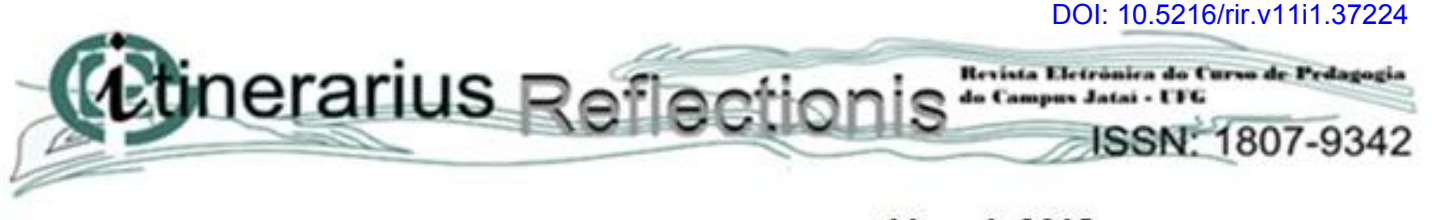

v.11, n. 1,2015

Diante disso, esta proposta vem se apoiar no referencial teórico da concepção sócio-histórica de desenvolvimento infantil, oriunda das teorias de Vigotski e seus seguidores Lúria (1998) e Leontiev (1998), além de buscarmos apoio também em autores brasileiros que se fundamentam nesse referencial.

De acordo com os estudos de Vigotski, no primeiro ano de vida, a criança tem uma sociabilidade totalmente especial em razão de uma situação social específica de desenvolvimento, determinada por dois momentos. Um consiste na capacidade biológica, visto que o bebê é incapaz de realizar qualquer atividade básica de sobrevivência. $\mathrm{O}$ adulto responsável é que cuida do bebê; dessa forma, suas primeiras relações são mediadas pelo adulto que o apresenta ao mundo social. Assim, é o adulto que desvela o universo social para ele. No segundo momento, embora o bebê dependa do adulto, ainda há carência da comunicação social - linguagem -. Como afirmam Arce e Silva (2009), em um primeiro momento tem-se o nascimento físico e biológico em que os adultos são responsáveis, são parteiros da vida social.

Vigotski buscou dentro do materialismo histórico e dialético ${ }^{3}$ de Marx e Engels subsídio para elaborar suas teorias. Estudou as relações sociais entre o indivíduo e o mundo exterior visando ao funcionamento psicológico e sua progressão junto ao processo histórico, bem como a relação do homem com o mundo mediado por meio de sistemas simbólicos.

Acreditamos que, antes de discorrer sobre o desenvolvimento infantil, dando ênfase à essa teoria, faz-se necessário entender a concepção de ser humano e sua relação com o trabalho. O conceito de Homem proposto por Marsiglia (2011, p. 5), como em outros estudiosos dessa perspectiva, o define como "como espécie, é um ser natural, isto é, é um ser composto biologicamente, mas que não está acabado, pois sua constituição depende das suas relações sociais". Nesse sentido, entendemos que essas relações sociais se dão pelo trabalho, o que diferencia os homens dos outros animais.

Assim, o ponto de partida dessa abordagem é o fato de que é por meio do trabalho que o homem se constitui enquanto sujeito, ou seja, por meio do trabalho, ele

\footnotetext{
3 Para maiores aprofundamentos consulte a obra de REGO, Teresa Cristina: VYGOTSKY: uma perspectiva Histórico-Cultural da Educação. São Paulo: Vozes, 1995.
} 


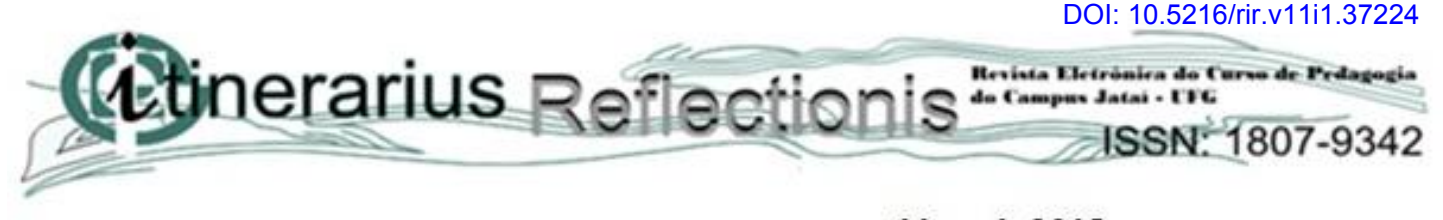

v.11, n. 1,2015

transforma o mundo e a si mesmo. Portanto, a produção material do homem tem um caráter universal. O trabalho é uma condição indissociável da natureza humana, e seu pressuposto é de que o homem esteja em condições de viver e criar meios de satisfazer suas necessidades e, consequentemente, escrever sua história.

Assim, a essência humana não é fruto da natureza, mas produzida por ele mesmo, ou seja, seu trabalho enquanto atividade de desenvolvimento social e humano é que o humaniza. Porquanto, no contexto da EI, entendemos que o espaço escolar da sala de aula deve privilegiar essa mesma construção humana, qual seja, o professor ao cuidar, ao brincar, está ensinando, está produzindo o humano no corpo da criança e sua relação com ela, passando pela alimentação, pelo brincar, pelo cantar, pelo movimentarse. Como afirma Arce (2013) o professor cria na criança sua "segunda natureza", é parteiro de seu nascimento para o mundo social.

Ademais, ao estabelecer essas relações dinâmicas entre a natureza e o espaço no qual está inserida, a criança vai, gradualmente, desenvolvendo-se, imprimindo seus modos de pensar e agir, sendo, por isso, modificada, alterando suas percepções sobre o espaço social. Assim, esses esquemas de produção material e produção de si mesmo é o que vai propiciar às crianças os elementos para sua própria construção enquanto sujeito.

A escola é, portanto, um espaço privilegiado de convivência humana, no qual as crianças vão compreendendo as estruturas do conhecimento e dele se apropriando, mediante o contato com o outro e com a natureza.

Justificando essa interpretação, na concepção sócio histórica criada por Vigotski, fica bastante clara essa relação dialética entre o social e o biológico, o que nos dá condição de compreender de forma diferente a partir dessa interação do biológico com o social, a origem e a evolução do psiquismo humano. Durante a constituição humana, dentro de um processo geral de desenvolvimento, segundo Vigotski, se é possível distinguir

[...] duas linhas qualitativamente diferentes de desenvolvimento, diferindo quanto à sua origem: de um lado, os processos elementares, que são de origem biológica; de outro, as funções psicológicas superiores, de origem sociocultural. A história do comportamento da 


\section{(titinerarius Renction 2

$$
\text { v.11, n. } 1,2015
$$

criança nasce do entrelaçamento dessas duas linhas (VYGOTSKY, 2003, p. 61).

A história do desenvolvimento das funções psicológicas superiores seria impossível sem um estudo da pré-história, de suas raízes biológicas e de seu arranjo orgânico.

À medida que a criança interage, relaciona-se com os adultos ou até mesmo com outras crianças mais experientes do seu grupo social, vai sendo fortemente influenciada a usar determinados objetos e adotar costumes de sua cultura. Ela é capaz de assimilar comportamentos tais como, cantar, andar, falar e até mesmo valores morais, disciplinares, que são construídos socialmente.

Vale destacar que essas propriedades de desenvolvimento dependem das condições concretas de vida, em qualquer idade. Isso significa dizer que crianças da mesma idade podem apresentar características de desenvolvimento diferentes umas das outras. Nesse sentido, o educador, especialmente o que lida com crianças de zero a cinco anos, deve propor ações não pelas conquistas já alcançadas pelas crianças, mas por aquilo que ela deverá alcançar. Por isso, voltamos a afirmar que o desenvolvimento não depende do simples fator biológico ou social, porém, de ambos. Assim, entendemos a importância do educador ao interferir de forma positiva e intencional a serviço do desenvolvimento da criança.

Um elemento fundamental para a compreensão dos conceitos vigotskianos sobre as questões psicológicas é o conceito de mediação. Para Vygotsky (2003) a estrutura das operações com signos requer um elo intermediário entre estímulo e a resposta. Este elo é o estímulo de segunda ordem (signo), colocando no interior da operação, preenchendo uma função especial, criando uma nova relação entre estímulo e resposta.

Para Rego (1995), é de fundamental importância que compreendamos a questão da mediação, a qual explica de que forma o homem se relaciona com o mundo e com os outros homens. A autora afirma que é por meio desse processo que as funções psicológicas superiores, especificamente humanas, se desenvolvem. Para falar de mediação, Vigotski se apropria de dois elementos básicos responsáveis por ela, o 


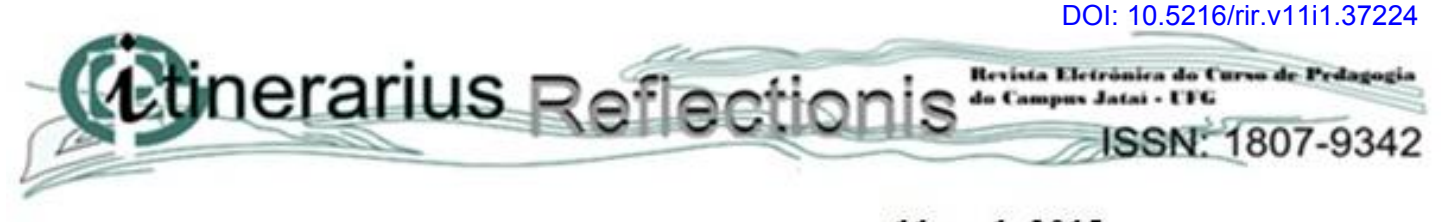

v.11, n. 1,2015

instrumento, o qual tem a função de regular as ações sobre os objetos; e o signo ${ }^{4}$, que regula as ações sobre o psiquismo humano.

Nesse sentido, podemos afirmar que os animais modificam o ambiente, entretanto, não são capazes de transformar o ambiente num momento específico, visto que não desenvolvem sua relação com o meio num processo cultural como faz o homem. Os instrumentos são elementos externos ao homem, capazes de provocar mudanças planejadas e significativas.

Segundo Vygostky (2003), a criação e organização social de instrumentos e de signos fazem-se conforme diferentes culturas e grupos sociais.

\begin{abstract}
A invenção e o uso dos signos como meios auxiliares para solucionar um dado problema psicológico (lembrar, comparar coisas, escolher) é análoga à invenção e uso de instrumentos, só que agora no campo psicológico. O signo age como instrumento da atividade psicológica de maneira análoga ao papel de um instrumento de trabalho (VYGOTSKY, 2003, p. 70).
\end{abstract}

Essas ferramentas são também chamadas por Vygotsky (2003) de “instrumentos psicológicos”, são orientados para o próprio sujeito, para sua dimensão interna. São ferramentas que auxiliam nas ações que exigem memória e atenção.

Os signos externos são imagens e representações, como por exemplo,

Quando uma pessoa ata um nó no lenço para ajudá-la a lembrar de algo, ela está, essencialmente, construindo o processo de memorização, fazendo com que um objeto externo relembre-se de algo; ela transforma o processo de lembrança numa atividade externa [...] os seres humanos por si mesmos, criam um elo temporário através de uma combinação artificial de estímulos (VYGOTSKY, 2003, p. 68).

Nesse sentido, entendemos que a memória é mediada por signos. Esses processos de mediação sofrem transformações ao longo do desenvolvimento do indivíduo. De acordo com Rego (1995), quando Vigotski trata da questão de uso de instrumentos para mediar as ações do ser humano, dedica particular atenção à aquisição da linguagem. A linguagem é assim

\footnotetext{
${ }^{4}$ Signo pode ser considerado como sendo um objeto, forma, fenômeno, gesto, figura ou ser, por exemplo, barbante amarrado no dedo para lembrar algo, uma música que lembra alguém, etc.
} 


\section{(tineraius Refo

entendida como um sistema simbólico fundamental em todos os grupos humanos, elaborado no curso da história social que organiza os signos em estruturas complexas e desempenha um papel imprescindível na formação das características psicológicas humanas (REGO, 1995, p. 53).

Sendo assim, pode-se dizer que tendo a linguagem (fala) como instrumento mediador, organizador das ações do homem, a partir dela, ele desenvolverá melhor aquelas características especificamente humanas, também chamadas de funções psicológicas superiores, por exemplo: pensar, lembrar, planejar, dentre outras.

Entendemos, assim, que um dos temas centrais na investigação de Vygotsky (2003) foi o surgimento do pensamento verbal e da linguagem como sistema de signos. Este sistema simbólico é básico em todos os grupos humanos. Na relação homem e mundo, o ser humano cresce num ambiente social, sendo de extrema importância a interação com o outro para o seu desenvolvimento. Essa importância trazida por Vigotski, que dá ao outro papel significativo no desenvolvimento do indivíduo, é formulada por um conceito essencial em sua teoria: o conceito de Zona de Desenvolvimento Próximo 5 .

Vigotski apresenta o conceito Zona de Desenvolvimento Próximo (ZDP) ao analisar as relações entre ensino e o desenvolvimento intelectual na idade escolar. Vigotski afirma que, para o desenvolvimento de uma criança é necessário não se deter naquilo que já amadureceu, também é preciso captar àquilo que está em processo de formação. Dessa forma, propõe dois níveis de desenvolvimento: o nível de desenvolvimento atual e a zona de desenvolvimento próximo. O desenvolvimento atual trata-se de um estágio do processo de aprendizagem em que a criança consegue fazer sozinha ou com a colaboração de colegas mais adiantados o que antes fazia com auxílio do professor, ou seja, dispensa a mediação do professor.

Conforme estudos de Vygotsky (2003), esse "fazer com a ajuda do outro" não anula, mas destaca a participação criadora da criança e serve para medir o seu nível de desenvolvimento intelectual, sua capacidade de discernimento, de tomar a iniciativa; como enfatizamos anteriormente, de começar a fazer por si só o que antes fazia com a

\footnotetext{
${ }^{5}$ No Brasil tem sido utilizado a tradução "proximal", mas adotaremos a tradução próximo, conforme estudos realizados. Maiores informações ver: DUARTE, Newton. A escola de Vigotski e a educação escolar. In: Educação escolar, teoria do cotidiano e a escola de Vigotski. Campinas-SP: Autores Associados, 2007. p. 75-106.
} 


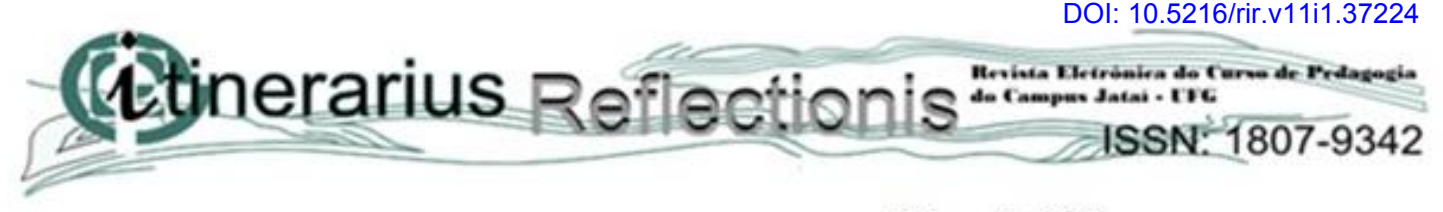

v.11, n. 1,2015

ajuda do outro, sendo um valioso critério de observação da eficácia do processo de ensino-aprendizagem.

Em síntese: a ZDP é constituída por aquilo que a criança, num determinado momento, não faz sozinha, mas o faz com ajuda de outro, inclusive do professor, e, para tanto, requer uma intervenção direta e sistematizada para a consecução do objeto pretendido. É nesta zona que o professor deve atuar, para torná-la desenvolvimento efetivo e avançar a um nível maior de conhecimento, fazendo com a criança e não por ela. Nesse sentido, observamos que Vigotski enfatiza que o bom ensino é o que atua nessa zona de desenvolvimento.

De acordo com Vygotsky (2003), o aprendizado é considerado um aspecto necessário e fundamental no processo de desenvolvimento das funções psicológicas superiores. Segundo este autor, todas as concepções decorrentes da relação entre desenvolvimento e aprendizagem podem ser reduzidas a três grandes teorias. O desenvolvimento humano pressupõe diversas fases da vida do indivíduo que ao se interrelacionarem com o meio ou com o objeto do conhecimento e, num determinado momento tem seu potencial evolutivo desvelado, a saber:

\begin{abstract}
A primeira centra-se no pressuposto de que os processos de desenvolvimento da criança são independentes do aprendizado. $\mathrm{O}$ aprendizado é considerado um processo puramente externo que não está envolvido ativamente no desenvolvimento. Ele simplesmente se utiliza dos avanços do desenvolvimento ao invés de fornecer um impulso para modificar seu curso (VYGOTSKY, 2003, p. 103-104).
\end{abstract}

A segunda grande posição teórica diz que a aprendizagem é desenvolvimento. Existem outras teorias que fazem essa mesma afirmação; uma delas postula que a aprendizagem se encontra totalmente integrada ao desenvolvimento, podendo concluir que os dois processos ocorrem juntos, aprendizado e desenvolvimento coincidem em todos os pontos. "O desenvolvimento é visto como o domínio dos reflexos condicionados, não importando se o que se considera é o ler, o escrever ou a aritmética" (VYGOTSKY, 2003, p. 105).

A terceira posição tenta superar os extremos das anteriores, combinando desenvolvimento e aprendizado, considerando os dois processos diretamente relacionados, um influenciando o outro. 
 \\ (therarius 20 2

\section{v.11, n. 1,2015}

Vygotsky (2003) rejeita essas três posições teóricas. Para ele, ao se fazer uma análise, é necessário considerar a relação gerada entre aprendizado e desenvolvimento e os fatores específicos desse envolvimento, quando a criança é inserida na atividade escolar. Ele acredita que "o aprendizado das crianças começa muito antes de elas frequentarem a escola. Qualquer situação com a qual a criança se defronta na escola, tem sempre uma história prévia" (VYGOTSKY, 2003, p.110).

Assim, o aprendizado da criança tem início em casa, no meio social em que vive, e quando entra na escola leva consigo todo um conhecimento internalizado desde seu nascimento. Dessa forma, quando analisamos o desenvolvimento de uma criança, conforme a teoria vigotskiana, o mais importante é deter-se naquilo que está em processo de formação e não o que a criança já sabe.

Considerando que a criança apropria do aprendizado, desde os primeiros contatos que mantém no seu meio social, é por meio da escola que ela adquirirá novos elementos no decorrer do seu desenvolvimento, o que pode ser chamado de conteúdos sistematizados. Concluindo, o que se apresenta como nível de desenvolvimento atual hoje, amanhã poderá se apresentar como nível próximo, e assim sucessivamente. O "bom aprendizado é somente aquele que se adianta ao desenvolvimento" (VYGOTSKY, 2003, p. 117). Entendemos então que o que impulsiona a criança a aprender é o desafio para que a criança utilize capacidades que ainda não estão consolidadas, para resolver situações de aprendizagens que estão na ZDP.

Analisando o contexto escolar, faz-se necessário que o professor selecione quais conteúdos se encontram em cada momento do processo na ZDP. Se o professor se limitar àquilo que já se formou na criança, o ensino se torna inútil. É importante também que não se exija da criança conteúdos que ela não pode ainda compreender, pois assim a criança fracassará, uma vez que suas capacidades cognitivas não estão devidamente construídas para a apreensão de determinado conteúdo.

Nesse contexto histórico, é que postulamos a importância do brinquedo cantado com crianças de zero a cinco anos, pois, ao brincar, vários esquemas das funções psicológicas superiores são acionadas, tais como: memória, linguagem, atenção, vontade, sentimento, dentre outros. 


\section{(titinerararius Reflection 2

\section{O BRINQUEDO CANTADO E SUA INSERÇÃO NA EDUCAÇÃO INFANTIL: ALGUMAS CONSIDERAÇÕES}

Como atividades associadas à infância, o brinquedo e o jogo requerem uma atenção especial e precisam ser investigados em suas múltiplas determinações. Historicamente apresentaram diferentes compreensões e foram utilizados para diversos fins.

Ao entendermos que há vários significados atribuídos ao brinquedo e ao jogo, faz-se necessário destacar aqui nossa compreensão sobre esses termos, uma vez que é a partir dela que desenvolveremos as reflexões sobre o brinquedo cantado.

Apoiados nas leituras realizadas e na concepção vigotskiana, entendemos que o brinquedo torna-se um aspecto fundamental para criar, ampliar as expectativas da zona de desenvolvimento próximo (VIGOTSKY, 2003, p. 129), pois:

\footnotetext{
No brinquedo a criança sempre se comporta além do comportamento habitual de sua idade, além de seu comportamento diário: no brinquedo é como se ela fosse maior do que é na realidade. Como no foco de uma lente de aumento, o brinquedo contém todas as tendências do desenvolvimento sob forma condensada, sendo ele mesmo uma grande fonte de desenvolvimento (VIGOTSKY, 2003, p. 129).
}

Dessa forma, podemos dizer que no brinquedo a criança representa papeis que muitas vezes encontra-se além do seu desenvolvimento atual, o que é extremamente importante na aquisição de novas atitudes, ações, comportamentos que poderão ser internalizados para usá-los em momentos posteriores.

O brinquedo provê uma situação de transição entre a ação da criança com objetos concretos e suas ações com significados, contribuindo para o seu desenvolvimento.

Além de propiciar a zona de desenvolvimento próximo, é no brinquedo que a criança consegue realizar ações que na verdade ela não poderia, isto é, satisfazer seus desejos imediatos brincando de faz de conta. Por exemplo, a criança brinca de médico, de policial, de ser professor, porque na idade em que se encontra seria impossível tudo isso; mas brincando ela se satisfaz, usa sua imaginação para tornar o impossível em realidade. 


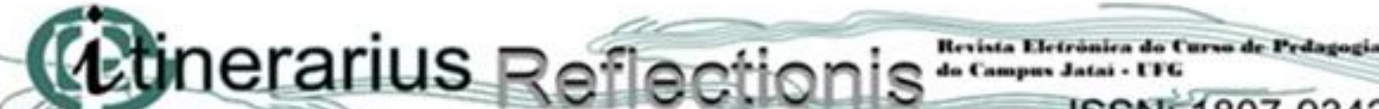 $\Delta$

A criança quer, ela mesma, guiar o carro; ela quer remar o barco sozinha, mas não pode agir assim, e não pode principalmente porque ainda não dominou e não pode dominar as operações exigidas pelas condições objetivas reais da ação dada (LEONTIEV, 2001, p. 121).

Segundo as premissas de Vigotski, por meio do brinquedo infantil é possível interpretar o processo de construção de representações ou jogo de papeis, o qual chama de jogo de "faz de conta". Assim, a criança é capaz de abstrair, criar uma situação imaginária, na qual os objetos ganham novos significados, novas utilidades.

Nesse imaginário, um pedaço de madeira vira revólver, uma lata vira avião; ela brinca de casinha, em que representa o papel de mãe, pai, irmão, etc. Pode-se dizer que essa situação imaginária pressupõe regras que provavelmente levarão a criança a se comportar de forma mais adiantada em relação ao momento real.

Leontiev (2001, p. 59), ao trabalhar sobre a teoria do desenvolvimento da psique infantil, afirmou que: "durante o desenvolvimento da criança, sob a influência das circunstâncias concretas de sua vida, o lugar que ele objetivamente ocupa no sistema das relações humanas se altera". Essa alteração das atividades na criança para a realidade humana pode acontecer de muitas formas, dentre elas, por meio do brinquedo. Segundo o autor, a criança penetra num mundo mais amplo, assimilando-o de forma eficaz.

O brinquedo é uma situação imaginária e uma atividade regida por regras. Mesmo no universo da brincadeira imaginária, há regras que devem ser seguidas, são essas regras que fazem com que a criança se comporte de forma mais avançada do que aquela habitual para sua idade, e também, aprende separar objeto de significado, como afirma Leontiev (2001):

Uma criança reconhece sua dependência das pessoas que a cercam diretamente. Ela tem de levar em conta as exigências, em relação a seu comportamento, das pessoas que a cercam, porque isto realmente determina suas relações pessoais, íntimas, com essas pessoas. Não apenas seus êxitos e seus malogros dependem dessas relações, como suas alegrias e tristezas também estão envolvidas com tais relações e têm a força de motivação (LEONTIEV, 2001, p. 60). 


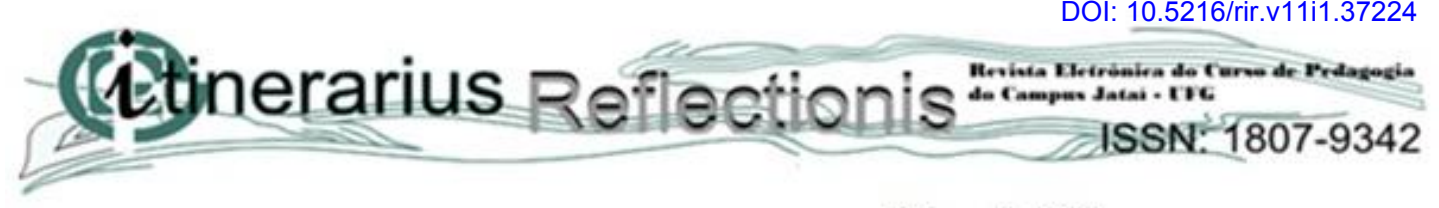

v.11, n. 1,2015

Nesse sentido, a promoção de atividades que favorecem o envolvimento da criança em brincadeiras, principalmente aquelas que promovem a criação de situações imaginárias, tem nítida função pedagógica. Segundo Luria (2001, p. 133), “em jogos subjetivos ou de enredo, a criança que brinca atribui-se uma função humana, a qual ela desempenha em suas ações".

Segundo Machado (1986), foi Froebel quem percebeu as contribuições dos brinquedos cantados na educação, prevendo o seu dinâmico poder intrínseco para juntar, na mesma atividade, jogo e música, sendo a sua mais eficiente expressão o coral, canto coletivo, entre outros.

\begin{abstract}
Brinquedos cantados dão às crianças estímulos sociais desinibindo-as, igualando-as aos companheiros socializados, desembaraçando-as. O simples fato de dar a mão numa roda torna a criança mais forte, mais segura com sentimento de cooperação. O brinquedo cantado é a forma mais simples de recreação para a criança. Por meio das "rodas ou rondas infantis" elas enriquecem seu vocabulário, aprendem a expressar-se, desinibir-se favorecendo também (a coeducação), a formação de grupos "mistos", visto que as crianças nesta idade têm interesses semelhantes (MACHADO, 1986, p. 167168).
\end{abstract}

Sendo assim, percebem-se as várias funções do brinquedo cantado, dentre as quais podemos destacar ações que criam condições para desenvolver valores sociais, desinibir, facilitar a criatividade, formar personalidade, desenvolver o vocabulário, trabalhar a pessoa de forma global.

Como toda brincadeira, o brinquedo cantado deve se adequar às necessidades e interesses das crianças envolvidas. Por meio do brinquedo cantado o professor poderá conhecer melhor seus alunos, pois, nesse momento, as crianças geralmente se revelam "naturalmente", sendo, portanto, um ótimo momento para se inteirarem. Enfim,

Os brinquedos cantados, não passam de um tipo elementar de jogo e melhor se aplicam às crianças de pouca idade, sobre os quais o ritmo das canções e da música exerce notável influência, facilitando-lhes muitos movimentos que seriam penosos e difíceis se, por acaso, não fossem auxiliados pela música (MACHADO, 1986, p. 168).

Logo, entendemos que a teoria vigotskiana do desenvolvimento infantil se encontra presente no brinquedo cantado, pois nele a criança faz uso da imitação, quando 


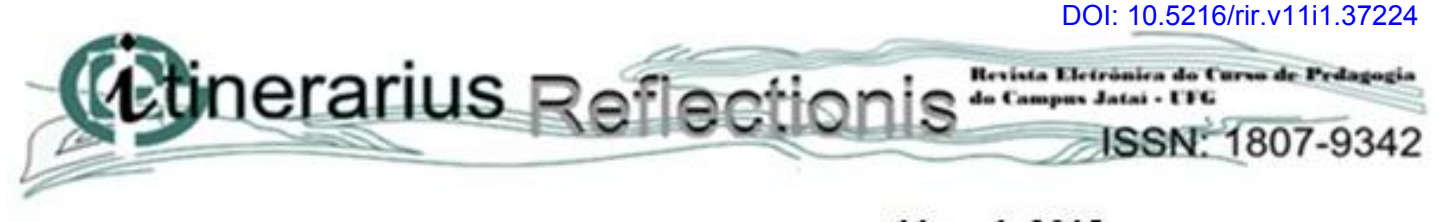

v.11, n. 1,2015

canta e gesticula, tendo como mediador da atividade os coleguinhas e a própria professora, possibilitando aí o surgimento da zona de desenvolvimento próximo. Terá, ainda, oportunidade de aprender com as outras pessoas, o que antes não conseguia, sem falar que é um momento riquíssimo de trabalho em grupo, onde o outro tem um papel de grande valor para que se efetive de fato a inter-relação social.

De acordo com os documentos do Referencial Curricular Nacional para a Educação Infantil (RCNEI),

\begin{abstract}
Brincar é uma das atividades fundamentais para o desenvolvimento da identidade e da autonomia. O fato de a criança, desde muito cedo, poder se comunicar por meio de gestos, sons e mais tarde representar determinado papel na brincadeira faz com que ela desenvolva sua imaginação. Nas brincadeiras as crianças podem desenvolver algumas capacidades importantes, tais como a atenção, a imitação, a memória, a imaginação. Amadurecem também algumas capacidades de socialização, por meio da interação e da utilização e experimentação de regras e papéis sociais (RCNEI, 1998, p. 22).
\end{abstract}

Isto significa dizer que o contato com maior número possível de atividades de diferentes situações comunicativas e expressivas resulta no desenvolvimento das capacidades linguísticas, de interação, de apropriação de diversos contextos.

Compreendemos que uma das tarefas da EI é ampliar essas capacidades nas crianças, por isso defendemos a importância do brinquedo cantado nessa etapa de educação. As instituições de EI devem possibilitar a todas as crianças a construção do conhecimento, buscando efetivamente uma educação na qual a aprendizagem aconteça. Para isso, o professor desta etapa de educação pode proporcionar esse trabalho com os brinquedos cantados. A construção de conceitos do mundo objetivo e subjetivo ocorre na ação do brincar.

De acordo com os RCNEI (1998),

Nas brincadeiras, as crianças transformam os conhecimentos que já possuíam anteriormente em conceitos gerais com os quais brinca. Por exemplo, para assumir um determinado papel numa brincadeira, a criança deve conhecer alguma de suas características. Seus conhecimentos provêm da imitação de alguém ou de algo conhecido, de uma experiência vivida na família ou em outros ambientes, do relato de um colega ou de um adulto, de cenas assistidas na televisão, no cinema ou narradas em livros etc. A fonte de seus conhecimentos é múltipla, mas estes encontram-se, ainda, fragmentados. É no ato de brincar que a criança estabelece os diferentes vínculos entre as 


\section{(titinerarius

características do papel assumido, suas competências e as relações que possuem com outros papéis, tomando consciência disto e generalizando para outras situações (RCNEI, 1998, p. 27-28).

Observamos que nessas brincadeiras a criança entra em contato com a cultura musical, aprende tradições musicais, possibilita a vivência com questões musicais, num exercício sensível e expressivo, que também oferece condições para o desenvolvimento de habilidades, formulação de hipóteses e elaboração de conceitos.

Nesse sentido, entendemos que o importante é que a criança brinque, uma vez que essa atividade contribui na estruturação do universo infantil, da expressão, do equilíbrio, da autoestima e autoconhecimento.

O brinquedo cantado mantém contato estreito e direto com as demais linguagens expressivas, além de ser um trabalho acessível às crianças de zero a cinco anos, inclusive àquelas que possuem necessidades especiais.

Com base na fundamentação teórica apresentada, concluímos que o brinquedo cantado é uma riquíssima metodologia do qual os educadores podem se apropriar, pois, por meio deste, considerado essencialmente uma situação de aprendizagem, as crianças poderão ampliar seu desenvolvimento e transformar os conhecimentos que já possuem em conceitos gerais, isto é, quando a criança assume algum papel numa brincadeira, ela deve conhecer alguma das características deste. Conforme os RCNEI (1998) exemplificam, os conhecimentos da criança provêm da imitação de alguém ou de algo que ela conhece, de uma experiência vivida na família ou em outros ambientes, do relato de um colega ou de um adulto, de cenas assistidas na televisão ou narradas em livros. Dessa forma, a fonte de seus conhecimentos é múltipla, mas estes encontram-se, ainda, fragmentados e, é no ato de brincar que a criança estabelece os diferentes vínculos entre as características do papel assumido e as relações que possuem com outros papeis, tomando consciência disto e generalizando para outras situações e construções de novos conceitos.

\section{REFERÊNCIAS}

ARCE, Alessandra. Pedagogia da infância ou fetichismo da infância? In: DUARTE, Newton (org.). Crítica ao fetichismo da individualidade. Campinas: Autores Associados, 2004, p.145-168. 


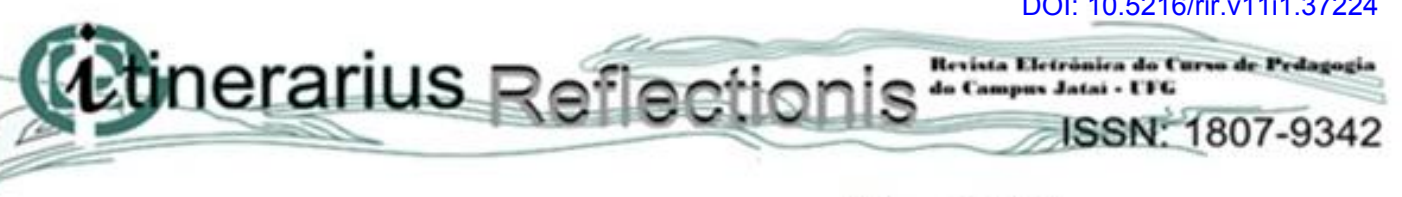

$$
\text { v.11, n. } 1,2015
$$

A brincadeira de papéis como produtora de alienação no Referencial Curricular Nacional da Educação Infantil. In: e NEWTON, Duarte (orgs.). Brincadeiras de papéis sociais na educação infantil: as contribuições de Vigotski, Leontiev e Elkonin. São Paulo: Xamã, 2006, p. 99-115.

O referencial curricular nacional para a educação infantil e o espontaneísmo. In: ARCE, A. e Martins, Ligia M. Quem tem medo de ensinar na educação infantil? Em defesa do ato de ensinar. Campinas: Alínea, 2007.p. 13-36.

e SILVA, Janaina Cassiano. É possível ensinar no berçário? O ensino como eixo articulador do trabalho com bebês (6 meses a 1 ano de idade). In: ARCE, A. e Martins, Ligia M. Ensinando aos pequenos: de zero a três anos. Campinas: Alínea, 2009. p.163185.

BRASIL. Ministério da Educação e do Desporto, Secretaria de Educação Fundamental. Referencial Curricular Nacional para a Educação Infantil. Brasília: MEC, SEF, 1998. (3 vol.).

DUARTE, Newton. A escola de Vigotski e a educação escolar. In: Educação escolar, teoria do cotidiano e a escola de Vigotski. Campinas-SP: Autores Associados, 2007. p. 75-106

GALVÃO, Isabel. Henri Wallon: uma concepção dialética do desenvolvimento infantil. Petrópolis, Editora Vozes, 1995.

LEONTIEV, A. N. Os princípios psicológicos da brincadeira pré-escolar. In: VIGOTSKII, L. S.; LURIA, A. R e LEONTIEV. A. N. Linguagem, desenvolvimento e aprendizagem. São Paulo: Ícone, 2001, p. 119-142.

MACHADO, Nilce V. Educação física e recreação para o pré-escolar. $3^{\mathrm{a}}$ ed. Porto Alegre: Podril, 1986.

MARSIGLIA, Ana Carolina Galvão. A prática pedagógica histórico-crítica na educação infantil e ensino fundamental. Campinas: Autores Associados, 2011.

REGO, Tereza Cristina. VYGOTSKY: Uma perspectiva histórico-cultural da educação. Petrópolis: Vozes, 1995.

VYGOTSKY, Lev Semenovich. Pensamento e linguagem. São Paulo: Martins Fontes, 1998/ 2003.

A formação social da mente. São Paulo: Martins Fontes, 2003/1998.

VIGOTSKII, L.S. Aprendizagem e desenvolvimento intelectual na idade escolar. In:__, LURIA, A.R e LEONTIEV, A.N. Linguagem, desenvolvimento e aprendizagem. São Paulo: Ícone, 2001, p. 103-117. 


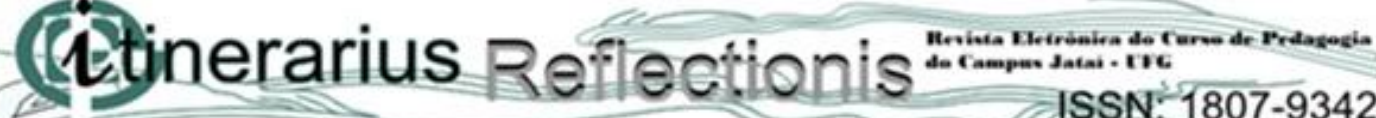

v.11, n. 1,2015 LURIA, A.R e LEONTIEV
aprendizagem. São Paulo: Ícone, 2001.

A.N. Linguagem, desenvolvimento e 